\title{
Research on Ideological and Political Construction of Physical Education Curriculum from the Perspective of Dissipative Structure Theory
}

\author{
Mengdie $\mathrm{Hu}^{1}$ and Lan Pang ${ }^{2, *}$ \\ ${ }^{1}$ School of Education, China University of Geosciences, M.S., Wuhan, Hubei 430074, China \\ ${ }^{2}$ School of Physical Education, China University of Geosciences, Prof., Wuhan, Hubei 430074, China \\ *Corresponding author.Email: panglan@cug.edu.cn
}

\begin{abstract}
This paper creatively introduces the dissipative structure theory of physics, providing a new path for colleges to improve their quality and efficiency of "building morality and cultivating people" in the physical education curriculum. After confirming it has the characteristics of openness, non-equilibrium, non-linear, and fluctuation, the authors take its operation mechanism as the logical order, correspondingly clarifying the difficulties in each stage one by one. The status quo demonstrates that the difficulties lie mainly in the implementation of openness and dominance, the consideration of integration and synergy, and the control of acceptability and contingency. Furthermore, we comprehensively put forward strategies for colleges, families, and community members. These points are interdisciplinary products, thus giving us unique innovative significance.
\end{abstract}

Keywords: dissipative structure theory, physical education curriculum, ideological and political education

\section{INTRODUCTION}

Jinping Xi emphasized that "sports carry the dream of national prosperity and national rejuvenation. Sports are strong while China is strong, while national sports are prosperous. " [1] The spirit of patriotic dedication, tenacious struggle, unity and cooperation embodied by physical education curriculum in the process of exceeding one's limitations not only has the unique advantages of deepening ideological and political education, but also endows it with innovative educational functions, and can highlight the embellishment of "building morality and cultivating people". Rational understanding and comprehensive grasp of the operation mechanism of the ideological and political construction of physical education curriculum is the need to increase the remarkable effect and radiation function of " all staff, the whole process, and the whole curriculum education". The introduction of dissipative structure theory is the practical call to broaden the interdisciplinary research perspective and actively promote optimal operation and improvement.

\section{CONFIRMATION OF DISSIPATIVE STRUCTURE OF IDEOLOGICAL AND POLITICAL EDUCATION IN P.E. CURRICULUM}

According to I. Prigogine's dissipative structure theory, to form a high-level "orderly" dissipative structure, an open system far from the equilibrium state must be established and self-organized by nonlinear action mechanism and fluctuation induced by various changes. This structure continuously consumes and diffuses material, energy, and information while also maintaining a stable and orderly structure in time, space, and function. An open system, far from equilibrium, nonlinear interaction, and fluctuation are the required and sufficient conditions, as well as the judgment foundation. The physical education curriculum's practicalness, competitiveness, diversity, collectedness, and interaction determine the objectivity of its ideological and political education's operation schema, displaying key traits of the dissipative structure.

\subsection{Ample Openness}

International news, sports events, and representative figures can serve as crucial carriers for ideological and political education. The physical education curriculum, in particular, has a unique "practicalness" that contributes to ideological and political education with distinctive educational advantages based on adequate exercise. And the primary 
teaching methods include physical training, physical quality development, and project skill acquisition. Learners can personally experience the hardworking spirit, sports humanistic sentiments, and professional quality condensed in it. Multiform, multi-channel, and open teaching practice is a special type of combination of " improve physical fitness " and " improve moral level ", which adds more vitality to the ideological and political education of physical education curriculum.

\subsection{Significantly away from Equilibrium}

There are two kinds of differences in the ideological and political education of physical education curriculum: one is the internal "realistic difference" and "individual difference"; the other is the "historical difference" between internal and external. The essential attribute of "competitiveness" of physical education significantly expands the dynamic function of the non-equilibrium condition of "individual differences". The "conflict" caused by competition urges individuals to focus on selfcertification, self-display, and self-improvement, firmly establish the awareness of equal competition and rules in learners' sports morality, and motivate students to achieve an all-round development with the psychological appeal of "pursuing excellence".

\subsection{Internal Nonlinear Action}

$" 1+1=2$ " is the simple expression of "linear action", yet "the entire universe, from macro to micro, is nonlinear in essence". [2] The elements in the ideological and political construction of physical education curriculum, for example, are intertwined and interrelated. Its assessment standard is the result of the joint action of "diversity" indicators, with ideal and belief, educational quality, professional quality, and personal development serving as the first level standard. Under the first level, there are 16 secondary standards with both systematic and independent. [3] In various linkages, the assessment points and standard levels of ideological and political education in the physical education curriculum are varied, and the corresponding teaching subjects and methods must be complex and diversified.

\subsection{Random Fluctuation}

"Fluctuation" is mainly reflected in the ups and downs of students' moral levels in the ideological and political education of physical education curriculum. As the result of the prominent " collectedness " and "interaction" of the physical education curriculum, the frequency and intensity of "fluctuation" in its ideological and political education would increase significantly. Multidirectional and active communication acts first on the teaching environment, then expands step by step under the nonlinear mechanism, and finally affects the effectiveness of ideological and political education in physical education curriculum, thus forming random "quantitative change" and "qualitative change". Therefore, "fluctuation" can not only reflect the current situation of students' moral level and indicate the advantages and disadvantages of the current physical education teaching system, but it can also be considered as a vital index for the ideological and political construction of physical education curriculum: to trigger a new stable and orderly state.

\section{DIFFICULTIES IN IDEOLOGICAL AND POLITICAL CONSTRUCTION OF P.E. CURRICULUM}

The report of the 2020 Shanghai college curriculum ideological and political education and teaching reform promotion meeting shows: drawing data support from the questionnaire survey of universities in 25 provinces and cities across the country, $57.9 \%$ of universities have no systematic ideological and political teaching training system, $54.2 \%$ of universities have no special characteristic ideological and political curriculum, and $72.9 \%$ of universities organize teachers to carry out systematic learning and training less than twice a semester. Based on this survey, from the perspective of the dissipative structure operation mechanism of ideological and political construction of physical education curriculum (Fig. 1), there must be difficulties needed to be deeply explored and accurately grasped in its operation process of "power generation--internal action--advanced order".

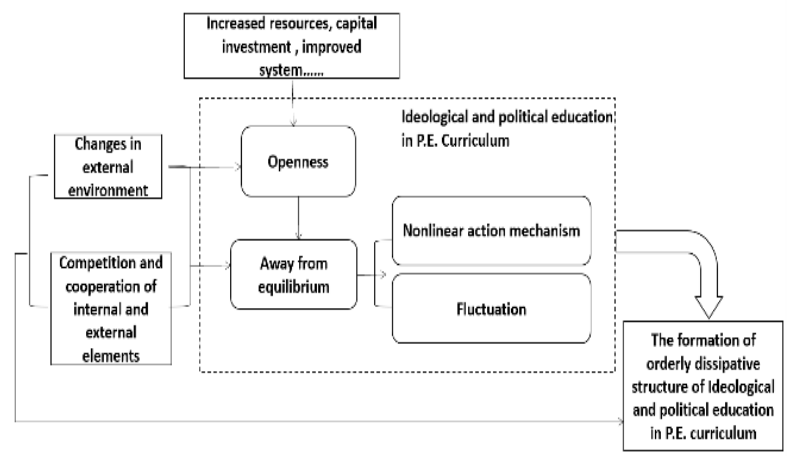

Figure 1. Dissipative structure operation mechanism of ideological and political construction of physical education curriculum

\subsection{Power Generation-Implementation of Openness and Dominance}

The power of developing students' ideological and moral levels in the physical education curriculum is dependent on the possibilities provided by "input" of ideological and political elements and the inexhaustible power of "nonequilibrium". Educators guide learners to recognize, select and restructure the meaningful ideological and political elements following its interchange between the subject and object of education and the society. A variety of 
contradictions created in the process accentuate the difference and heterogeneity. The collision of this contradiction finally leads to the occurrence of power.

First, it is difficult to deeply excavate and give full play to the advantages of "practical" ideological and political resources. Practical challenges such as fund investment, potential safety hazards, and curriculum arrangement make it difficult for colleges and universities to build a practical teaching platform with off-campus institutions, leading to form a physical closure. Some students are passive in learning attitude and exercise attendance. They disregard the critical role of ideological and political education in spiritual nourishment, go against the great expectations of young people in the new era, thus forming a psychological closure. Therefore, the increasing limitation of advantageous practice resources, along with a lack of students' enthusiasm exacerbates the problem of "selfclosure".

Second, it is difficult to execute the leading position of physical education teachers in the ideological and political education of the physical education curriculum. Teaches, as the organizer and implementer of the physical education curriculum, are the primary guarantee for realizing the goal of "building up the physique and casting the soul". However, there is currently no comprehensive system norms, as well as an appropriate incentive mechanism and training scheme, which causes some physical education teachers to lack relevant abilities, such as a weak subjective will for reform, insufficient ability of educational reform, and low self-consciousness in educating people. It is easy to be confused about the value or choose to escape facing many difficulties in the ideological and political reform of the physical education curriculum.

\subsection{Internal Action-Consideration of Integration and Synergy}

The influencing variables of the nonlinear mechanism range from school leaders, managers, teachers, and learners to individual ideological systems, knowledge structure, emotional will, implicit infection of environment, and peer communication. Given the complexities and diversity of the "physical training" mission and the educational impact of physical education curriculum, we should pay special attention to the relationship between the acquisition of physical education knowledge and skills and the cultivation of ideology and morality, which necessitates the coordinated role of educational subjects in the same direction.

First, it is difficult to in-depth integrate sports professional knowledge and skills with ideological and political education. In the content of the physical education curriculum, " ideological and political curriculum " does not mean implanting ideological and political elements such as patriotism, sports spirit, ideal and belief, and scientific spirit superficially in physical education. Simultaneously, the diversified athletic activities are difficult to make unified induction and generalization in the field of ideological and political. As to the form of the physical education curriculum, there are some current problems, such as simply calling for ideological and political slogans by rote and farfetched. The stubborn disease of "two skins" is also the dilemma of "linear addition", consequently it's momentous to set the curriculum closing to students' majors and deriving from fresh cases as to firmly grasp its "soul".

Second, it is difficult to construct and improve the "community" of ideological and political education in the physical education curriculum. An obvious "island" phenomenon results from the erosion of the concept of cooperative education among educational subjects. Some physical education teachers are prejudiced against ideological and political education, generally believing that it should be the responsibility of professional teachers and counsellors. Some universities lack overall planning for the implementation, regulation, and guarantee of ideological and political work in the physical education curriculum.

Both the leading department and management department accomplish their separate duties, while physical education teachers' ideological and political integration capacity is passivated. Therefore, the construction of a "great ideological and political pattern" in universities is fraught with danger, resulting in the divergence and dispersion of educational links, a lack of interaction, and even back to confrontation.

\subsection{Advanced Order-Control of Acceptability and Contingency}

On the basis of the first two stages, students independently choose ideological and political elements according to their psychological cognitive structure and internalize them in their hearts. Then, externalized in reality, gradually transformed into the practical and reflective construction of physical education. The "ups and downs" of students' ideology and morality not only have the microwave effect of whether it is fundamentally impacted but also have powerful ones that promote the qualitative change of ideological and moral level. The group activities in the physical education curriculum, without a doubt, complicate the intensity and frequency of "fluctuation", thereby further also introducing two main issues.

First, it is difficult to possess students' high recognition and acceptance. The physical education curriculum should make students willing to accept and identify with the transmitted values in the learning process of sports knowledge and skills. Simultaneously, adhering to students' physical and mental development law and demand, to awaken their independent thinking ability, especially self-understanding and ideological collision. Only students' wholehearted devotion and all-around influence among peers can promote individuals to actively transform their ideas, beliefs, and moral behaviour.

Second, the difficulty lies in collective interaction monitorization, keen observation, and teaching according to the situation. "An ideal teacher should play a limited but necessary role in accelerating the 'gradual or oscillatory 
period' and 'plateau period' for students, while no teacher can do anything about the 'sudden change' or leap in students' final understanding". [4] However, "necessity is always hidden behind a large number of contingencies in ideological and political education", [5] in order to grasp the necessity in contingency, the problem is in physical education teachers' acute discrimination, picking opportunities and strategies, efficient guiding, coordinating the collective, and creating a positive "ups" collective curricular teaching scenario.

\section{THE PATH OF IDEOLOGICAL AND POLITICAL CONSTRUCTION OF P.E. CURRICULUM}

\subsection{Cultivate Synergy and Constantly Enhance the Ideological and Political Vitality of P.E. Curriculum}

Before constructing a comprehensive coordination mechanism, we must thoroughly exploit the ideological and political features of the physical education curriculum, vigorously expand the educational force, and inject more vitality into the main channel. To begin, forcefully open up the ideological and political resources of the physical education curriculum. On the theoretical carriers, we should consider sporting events to be the natural soil of patriotism education, sporting personalities such as Haifeng Xu to be the fulcrum of moral education, and cross-domain knowledge courses to be the supplemental resource base. In terms of practical activities, sports exercises will be longterm and life-oriented and bring perseverance and selfimprovement throughout students' struggling life courses, with the help of activities such as campus sports meetings, sports competitions, internship training, and off-campus cooperation practice platform. The second is the inclusion of more educational subjects in the physical education curriculum. Families, schools, and community members may all serve as ideological and political educators. At the same time, accountability, security, and incentive mechanism can be established to fundamentally address the issues of unclear responsibilities and insufficient motivation. Following the procedures above, it is critical to form an organic integrated educational force to bring the scattered into order. As the main force of ideological and political education of physical education curriculum, the school should first ensure the top-level design of ideological and political education in physical education curriculum goes hand in hand with moral education. Then make an overall plan in terms of organization and leadership, fund guarantee, and implementation scheme. Secondly, by building a cooperation platform and a regular communication channel for the whole school staff, we can mobilize the excitement and creativity of physical education teachers. Finally, the long-term operation of the coordination mechanism needs to be maintained and enhanced in terms of assessment, supervision, and evaluation.

\subsection{Innovate the Teaching Mode and Deeply Integrate the Elements of Ideological and Political Education in P.E. Curriculum}

\begin{abstract}
"Non-linearity" and "non-equilibrium" as the "origin" and "source" of dissipative structure raise the requirements for pluralism and innovation. To enhance the integration of professional knowledge and skills of physical education and ideological and political education, we must strengthen teachers' leadership roles and innovate diverse teaching methods. Physical education teachers should provide students with rich, diversified, flexible, and trendy curriculum content, and make every effort to integrate collectivism, self-improvement, and entrepreneurship into the whole teaching process. Furthermore, they should change the antiquated idea and reserve more flexibility and freedom for the ideological and political education of the physical education curriculum. For the improvement of physical education teachers themselves, it's vital to pay close attention to the status of their own ideological and moral quality and combine it with the teacher's professional ability development, serving as an example for students. Second, in addition to the common example demonstration method, reward and punishment method, and emotional cultivation method, colleges physical education should be good at applying new ideological and political education modes, such as scenario creation method, difficulty setting method, and special education method. Extending the connotation and extension of curriculum education on the basis of following the law of students' physical and mental development and the learning characteristics of physical education curriculum, so as to strengthen their physique, improve their personality, temper their will and broaden their horizons.
\end{abstract}

\subsection{Pay Attention to Random Fluctuation and Fully Realize the Effectiveness of Ideological and Political Education in P.E. Curriculum}

By means of students' psychological dynamic investigation chart, non-guiding heart-to-heart talk, moral behaviour observation, and daily feedback, teachers can comprehensively grasp the development trends of students' ideological and moral quality. Hence there is a basis to follow, using educational reinforcement and warning to expand the "ups" in a harmonious teacher-student relationship. The preceding practice promotes the formation of ideology and morality, mitigates the negative influence of "downs", and seizes the dynamic chance of "nonequilibrium". However, the "fluctuation" of students' thoughts is often difficult to comprehend. As a result, teachers need to artificially construct a favourable physical education atmosphere, assist students via reflection to accomplish self-adjustment and sublimation, and guide 
students to actively reshape correct values and world outlook. Taking the Olympic champion of the "national table-tennis team" of the Tokyo Olympic Games as an example, when explaining and teaching the techniques and skills of Long Ma who won the first prize in the world, physical education teachers took advantage of the successful winning cases with high emotions to deepen students' ideological and moral qualities just like the sense of belonging and honour. Immediately, providing the possibility and realistic opportunity for the independent generation and deepening planting of students' ideological and moral character. Meanwhile, paying close attention to the physical performance and emotional fluctuation of students at each moment can also test the effectiveness of physical education courses, and promote the selection of appropriate educational measures and the artificial creation of correct teaching situations.

\section{CONCLUSION}

The ideological and political construction of physical education curriculum can ensure that students enjoy the fun brought by sports under the guarantee of their physical enhancement. It can promote individuals to raise their will to a new level in physical learning and exercise, and form a sustainable driving force for individual development. Macroscopically, finding the best educational annotation for sports to become a landmark career of the great rejuvenation of the Chinese nation.[6] To optimize the construction and improvement of ideological and political education in China's physical education curriculum with the theory of dissipative structure, we must not only deal with some difficulties in the operation of its mechanism but also form a sound theoretical learning mechanism, support the practical application paradigm, and ensure incentive measures. At present, universities can use this theory to incorporate its key ideas into all aspects of physical education curriculum and teaching practice (from the "input" of the political element to the "output" of talent resources), as well as to inject new vitality and impetus into its innovation process. Of course, this is not achieved overnight. Exploration of methodologies, identification of issues, implementation of plans, and summarization of experience in the construction of ideological and political education of physical education curriculum are all required. As an open dynamic system once I. Prigogine mentioned, only in this way can we make the research on the construction of ideological and political education of physical education curriculum move forward steadily according to the predetermined direction and route of "building morality and cultivating people".

\section{REFERENCES}

[1] Jinping Xi. Create a new situation in China's sports cause and speed up China's construction of a sports power[N]. People's Daily,2017-08-28(01). (In Chinese)

[2] Jie $\mathrm{Wu}$, Hongfang Li. Is nonlinearity the essence of nature? $[\mathrm{J}]$. Science and technology and Dialectics, 2000(2). (In Chinese)

[3] Cuixiang Dong, Sanming Fan, Yanli Gao.

Theoretical basis and structural system construction of Ideological and political elements in Physical Education Curriculum[J]. Journal of Physical Education,2021(1):7-13. (In Chinese)

[4] Xiaoyong Mu. The role of teachers: realizing the effective transformation of culture and Science[J]. Educational Theory and Practice, 2002,32(10):26-29. (In Chinese)

[5] Yaocan Zhang, Yongting Zhen. Modern ideological and political pedagogy[M]. Beijing: People's publishing house, 2006:80,117. (In Chinese)

[6] Fuxue Zhao, Zhuangzhuang Li. General Secretary Xi Jinping's important discourse on sports integration into the study of the construction of the physical education curriculum[J]. Journal of Wuhan Institute of Physical Education,2021(3):12-19. (In Chinese) 